\title{
Perodua Myvi engine fuel consumption map and fuel economy vehicle simulation on the drive cycles based on Malaysian roads
}

\author{
Muhammad Iftishah Ramdan ${ }^{1, *}$ \\ ${ }^{1}$ School of Mechanical Engineering, Universiti Sains Malaysia, 14000 Nibong Tebal, Penang, \\ Malaysia
}

\begin{abstract}
This paper presents the fuel consumption engine map for a $1.3 \mathrm{~L}$ Perodua Myvi passenger car. The engine dynamometer and the engine throttle are controlled, to create the operating conditions for the engine map. Interpolation work is done in MATLAB, to create a $3 \mathrm{D}$ fuel consumption engine map. The engine map is used in a fuel-economy estimation simulation, using the city and the highway drive cycles based on Malaysian roads. The fuel economy values generated from the simulations are similar to experimental fuel consumption results.
\end{abstract}

\section{Introduction}

Malaysia is a rapidly developing country in Asia, where the demand for passenger cars increases every year. The average car production in Malaysia is 24,403 units from 1984 until 2016, with maximum production of 56,745 units in April 2015 [1]. Perodua Myvi remained the best-selling car in Malaysia for eight consecutive years, between 2006 and 2013 [2]. Thus, it is important to study its fuel consumption performance as a measure of energy optimization.

A fuel consumption engine map refers to a 3-dimensional plot contour of fuel consumption on torque-speed maps, to show the engine fuel consumptions at given torquespeed combinations [3]. The engine's torque and speed can be measured using a load device called an engine dynamometer. Ramasamy [4] has previously built a brake specific fuel consumption (BSFC) map for K3-VE Perodua Myvi engine that presents the fuel consumption at wide-open throttle (WOT) condition. However, the map is not enough for vehicle simulations that estimate fuel economy. This is because any vehicle simulation would use broad range of speed and torque and not only at WOT condition.

In this study, a Perodua Myvi K3-VE engine is attached to an engine dynamometer. Its' throttle, along with the dynamometer load, are controlled simultaneously, to achieve the desired engine torque and speed. At the same time, the fuel consumed at the desired engine torque and speed, is recorded. The engine speed ranges from 1000 to $4500 \mathrm{RPM}$, and the torque is increased from $10 \mathrm{Nm}$ at increments of $10 \mathrm{Nm}$ until the engine stalls. The gathered fuel consumption data are then compiled and interpolated to create a $3 \mathrm{D}$ fuel consumption

* Corresponding author: shahramdan@usm.my 
engine map. The engine map is very useful for any vehicle fuel economy simulation to represent its engine model.

This paper also presents the simulation work to estimate the fuel economy of a Perodua Myvi 1.3L automatic on Malaysian drive cycles. Although there is an effort to establish a Malaysian drive cycle [13], there is no official one published yet. Thus, paper uses two drive cycles data that are based on driving on roads in Alor Star, Kedah, Malaysia [5]. The simulation utilizes the fuel economy engine map generated from the dynamometer measurements to calculate the estimated fuel consumption. The fuel economy results from the simulations and the actual experiment [5] are compared and discussed.

\section{Experimental setup}

The experiment intends to obtain the fuel consumption values of the engine at different combinations of engine torque and speed. The engine has to be subjected to controlled loads in order to generate specific torque values. Thus, an eddy current engine dynamometer is connected to a K3-VE engine flywheel (fig. 1).

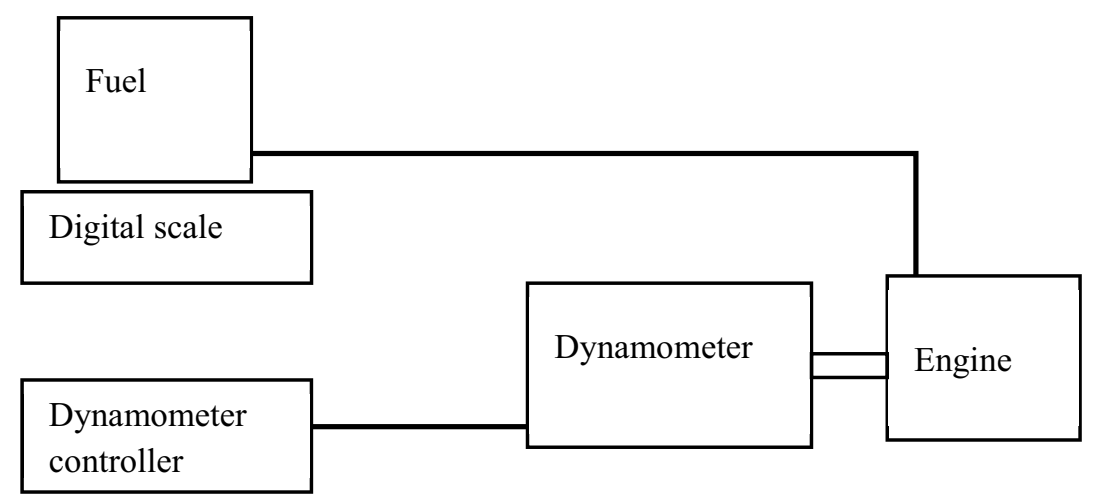

Fig. 1. Engine and dynamometer setup.

The experiment starts as the warmed-up engine reaches the desired torque and speed by controlling the engine throttle angle, and the dynamometer controller simultaneously. The engine speeds are varied from 1000 RPM to 4500 RPM, at increments of 500 RPM. At every speed, the torque values start at $10 \mathrm{Nm}$, and are increased at $10 \mathrm{Nm}$ increments until the engine is stalled at a wide-open throttle (WOT).

Once the desired torque and speed are obtained, the fuel consumption value is collected gravimetrically, where the difference in the fuel mass is calculated. The fuel container is placed on top of a digital weight scale that is used to measure its initial and the final mass during 30 seconds of fuel consumption. The difference between the initial and the final weights is then divided by 30 seconds to obtain the mass of fuel consumed for every second (in $\mathrm{g} / \mathrm{sec}$ ) (equation 1). The experiment is run twice, and the average of the two fuel consumption values, is used. In this study, the fuel consumption data are gathered and plotted for 64 combinations of torque and speed in a 3D fuel consumption engine map (figure 3).

$$
\text { Fuel consumption }=\frac{\text { Mass }_{\text {initial }} \text { Mass }_{\text {final }}}{30 \mathrm{sec}}
$$




\section{Mathematical modelling and simulation}

\subsection{Vehicle mathematical modeling, control strategy and simulation algorithm}

The simulation algorithm reads the vehicle speed from a drive cycle [5] and discretizes it into one-second time steps. At every time step, the average speed and acceleration of the vehicle from a drive cycle, are fed into the vehicle model to calculate the acceleration, the tractive force, and the torque needed at the wheels (equation 2 to equation 7) [12]. The simulation uses a four-speed, automatic transmission 1.3L Perodua Myvi's parameters (table 1) as its mathematical vehicle model.

Table 1. Automatic Perodua Myvi parameters [6,7].

\begin{tabular}{|c|c|c|c|}
\hline Maximum engine torque & Tengine & & $116 \mathrm{Nm}$ \\
\hline \multirow[t]{4}{*}{$\begin{array}{l}\text { Total gear ratio (gear } \\
\text { ratio x final drive ratio) }\end{array}$} & \multirow[t]{4}{*}{ Gratio } & $\begin{array}{c}1 \text { st } \\
\text { gear }\end{array}$ & 11.01 \\
\hline & & $\begin{array}{l}\text { 2nd } \\
\text { gear }\end{array}$ & 6.15 \\
\hline & & $\begin{array}{l}\text { 3rd } \\
\text { gear }\end{array}$ & 4.03 \\
\hline & & $\begin{array}{l}\text { 4th } \\
\text { gear }\end{array}$ & 2.81 \\
\hline $\begin{array}{l}\text { Efficiency of } \\
\text { transmission }\end{array}$ & $\eta t$ & & 0.85 \\
\hline Tire radius & Rtire & & $0.288 \mathrm{~m}$ \\
\hline Frontal area & $\mathbf{A}$ & & $2306 \mathrm{~m} 2$ \\
\hline Air drag coefficient & Cd & & 0.32 \\
\hline Air density & $\rho$ & & $\begin{array}{l}1.225 \\
\mathrm{~kg} / \mathrm{m} 3\end{array}$ \\
\hline Mass of vehicle + driver & $\mathbf{m}$ & & $1055 \mathrm{~kg}$ \\
\hline $\begin{array}{l}\text { Coefficient of rolling } \\
\text { resistance }\end{array}$ & $\mathrm{Cr}$ & & $0.01 \dagger$ \\
\hline
\end{tabular}

*("Rolling friction and rolling resistance,")

At every time step, the vehicle wheels have to overcome four forces in order to move. They are the air drag force $\left(\mathrm{F}_{\text {air }}\right)$, the force of slope of the road $\left(\mathrm{F}_{\text {slope }}\right)$, the acceleration force $\left(\mathrm{F}_{\text {acceleration }}\right)$, and the rolling resistance $\left(\mathrm{F}_{\text {rolling }}\right)$. The sum of these forces is equal to the tractive force of the driving wheels $\left(\mathrm{F}_{\text {wheel }}\right)$ (Equation 2).

$$
F_{\text {wheel }}=F_{\text {air }}+F_{\text {slope }}+F_{\text {acceleration }}+F_{\text {rolling }}
$$


The air drag force is calculated using equation (3), where $\rho$ is the density of air $\left(\mathrm{kg} / \mathrm{m}^{3}\right)$, $\mathrm{v}$ is velocity of the vehicle $(\mathrm{m} / \mathrm{s}), \mathrm{C}_{\mathrm{d}}$ is the air drag coefficient, and $\mathrm{A}$ is the frontal area of the vehicle $\left(\mathrm{m}^{2}\right)$.

$$
F_{\text {air }}=\frac{1}{2} \rho v^{2} C_{d} A
$$

Equation 4 shows the calculation for the force caused by the gradient, or slope, of the road, where $\mathrm{m}$ is the sum of the masses of the vehicle and the driver $(\mathrm{kg}), \mathrm{g}$ is the gravity acceleration $\left(\mathrm{m} / \mathrm{s}^{2}\right)$, and $\alpha$ is angle of slope of the road $\left({ }^{\circ}\right)$. In this paper, the angle of slope is assumed to be zero, because most parts of the roads used in drive cycle are levelled.

$$
F_{\text {slope }}=m g \sin \alpha
$$

The force caused by vehicle acceleration is shown in equation 5 , where $\mathrm{m}$ is the sum of the masses of the vehicle and the driver $(\mathrm{kg})$, and $a$ is the vehicle's acceleration $\left(\mathrm{m} / \mathrm{s}^{2}\right)$.

$$
F_{\text {acceleration }}=m a
$$

The rolling resistance is caused by the tires' contact patches that resist the movement of the tires (equation 6), where $C_{r}$ is the rolling resistance coefficient [8], $m$ is the sum of the masses of the vehicle and the driver $(\mathrm{kg})$, and $g$ is the gravity acceleration $\left(\mathrm{m} / \mathrm{s}^{2}\right)$.

$$
F_{\text {rolling }}=C_{r} m g
$$

From the calculated tractive force at the wheels $\left(\mathrm{F}_{\text {wheel }}\right)$, the wheel torque can be calculated by using equation.

$$
\mathrm{T}_{\text {wheel }}=\mathrm{F}_{\text {wheel }} \mathrm{R}_{\text {tire }}
$$

Where $T_{\text {wheel }}$ is the wheel torque $(\mathrm{Nm}), \mathrm{F}_{\text {wheel }}$ is the total tractive force of driving wheels $(\mathrm{N})$. The engine torque $\left(\mathrm{T}_{\text {engine }}\right)$ and the engine speed $\left(\omega_{\text {engine }}\right)$ are determined from equations 8 and equation 9 respectively, which involve the gear ratio $\left(G_{\text {ratio }}\right) . G_{\text {ratio }}$ is selected, by following a simple, rule-based control strategy algorithm, as shown in table 2 . The engine torque (equation 8 ) is also influenced by the transmission efficiency $\left(\eta_{t}\right)$ which models the losses of the drive train.

$$
\begin{gathered}
\mathrm{T}_{\text {engine }}=\mathrm{T}_{\text {wheel }} / \mathrm{G}_{\text {ratio }} / \eta_{\mathrm{t}} \\
\omega_{\text {engine }}=\omega_{\text {wheel }} \mathrm{G}_{\text {ratio }}
\end{gathered}
$$

Table 2. Gear selection rules.

\begin{tabular}{|c|c|}
\hline Speed $(\mathbf{m} / \mathbf{s})$ & Gears \\
\hline$<7.73$ & 1 \\
\hline 7.73 to 13.83 & 2 \\
\hline 13.83 to 21.09 & 3 \\
\hline$>21.09$ & 4 \\
\hline
\end{tabular}

The combination of the engine torque and speed are used to estimate the fuel consumption from the fuel consumption engine map obtained experimentally (figure 3 ). 
The total fuel consumption from all the time steps is obtained, to calculate the fuel economy of the vehicle operating on every drive cycle by using equation (10).

$$
\text { Fuel Economy }(\mathrm{km} / L)=\frac{D T}{F C T}
$$

Where DT is the total distance travelled $(\mathrm{km})$, and FCT is the total volume of the fuel consumed (L).

This paper presents the results from two simulations, with a different drive cycle in each simulation. One of the drive cycles represents city driving conditions, with a low-speed, frequent start-and-stop pattern. The other one represents a highway drive cycle, with a highspeed, in frequent start-and-stop driving pattern. The simulation fuel economy results are compared to actual fuel economy values obtained during the development of the drive cycles [5]. The overall simulation can be summarized in simulation diagram (figure 2).



Fig. 2. Simulation algorithm.

\section{Results and discussion}

The 64 experimental fuel consumption data points are used to construct the $3 \mathrm{D}$ engine fuel consumption map using the 'nearest' interpolation function in MATLAB (figure 3). The 3D fuel consumption map presented here is used in the simulation to calculate the estimated fuel consumption. 


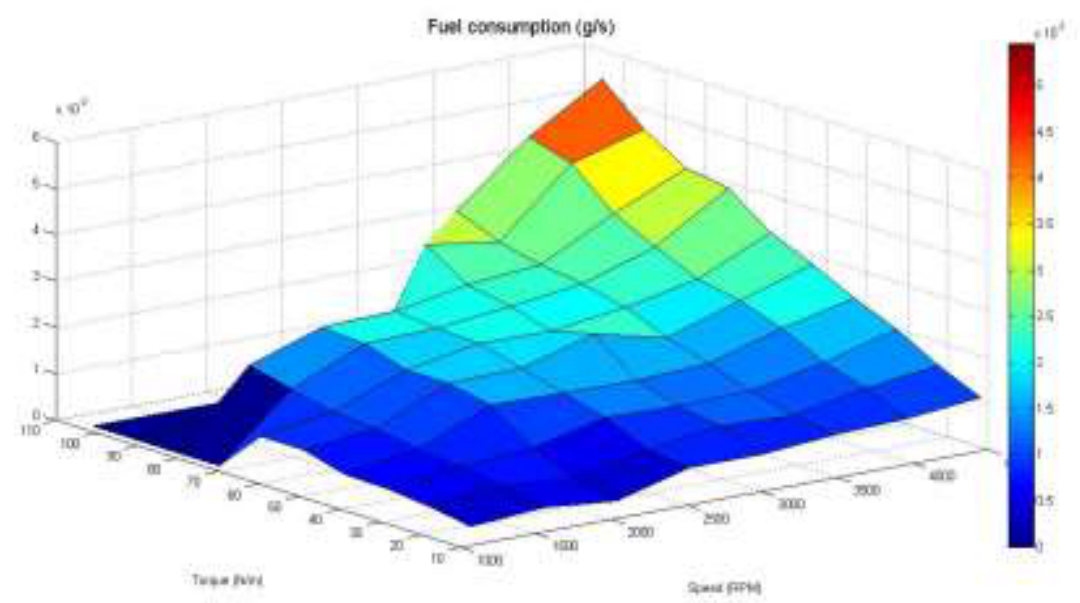

Fig. 3. 3D fuel consumption engine map.

\subsection{Simulation and experimental fuel economy}

The vehicle mathematical model is simulated on a city drive cycle and a highway drive cycle. The city drive cycle consists of 1,738 seconds of high-frequency stop-and-go driving conditions and low speeds, with the maximum speed of $19.5 \mathrm{~m} / \mathrm{s}(70.2 \mathrm{~km} / \mathrm{h})$. The vehicle only utilizes the first, the second, and the third gears, with engine speeds of less than 3,000 RPM required to drive on this drive cycle (figure 4).

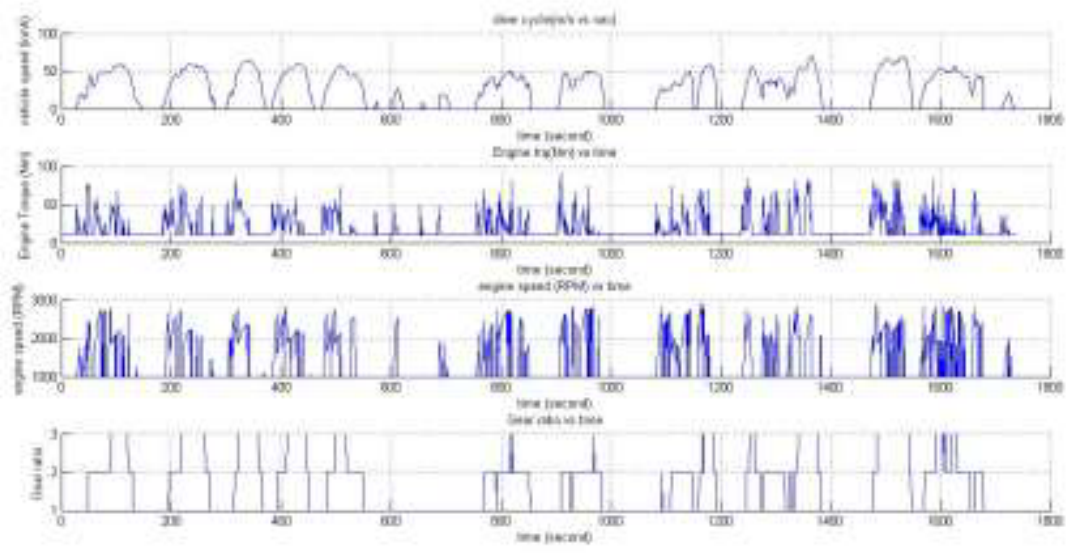

Fig. 4. Vehicle operating conditions for city drive cycle. 


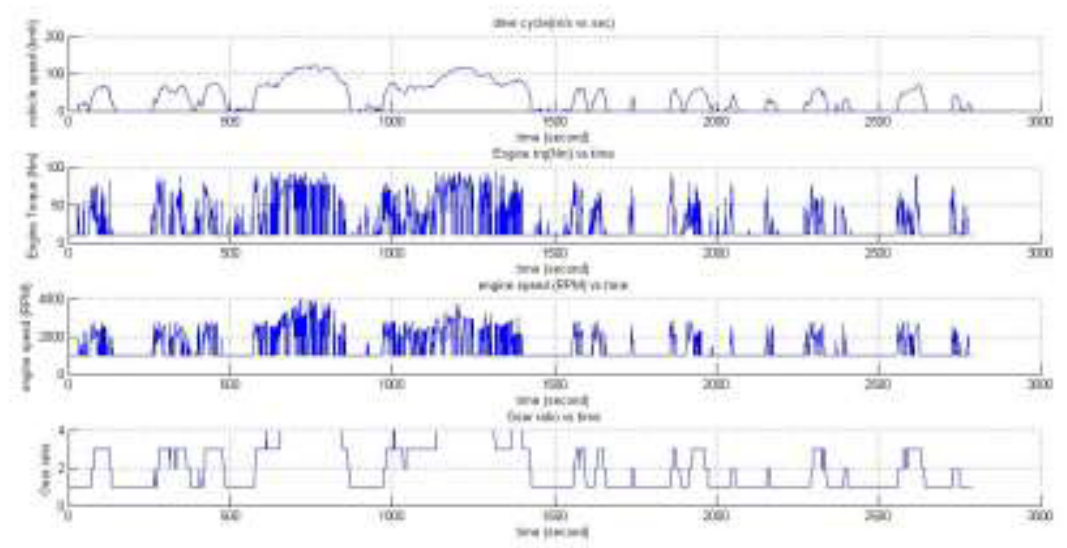

Fig. 5. Vehicle operating conditions for the highway drive cycle.

The highway drive cycle, on the other hand, consists of 2,878 seconds of low-frequency stop-and-go driving conditions and high speeds, with the maximum speed of $33.37 \mathrm{~m} / \mathrm{s}$ $(120.13 \mathrm{~km} / \mathrm{h})$. The vehicle utilizes all four gears, with the engine speeds of up to 4000 RPM required to drive on this drive cycle (figure 5).

The fuel economy values from the simulations are compared to the actual ones, as shown in table 3 . The fuel economy of the vehicle driven on highway drive cycle is better compared to that when the car is driven on the city drive cycle. This is because the highway drive cycle requires less acceleration than the city drive cycle, which contributes to high torque (and power) demands from the wheel (equations 2 and 5).

All in all, the simulation and the actual fuel economy results from both drive cycles are similar, with percentage differences of less than $5 \%$. The difference is due to the absence of transient elements from the simulation. The fuel consumption engine map used in the simulation records the fuel consumption when the engine reaches steady state torques and speeds. The difference of results between the steady-state and transient were mentioned by Z. Gao [9]. However, for estimation purpose, this simulation method is adequate as shown by the small difference in the simulation and the actual fuel economy results.

Table 3. Simulation and real (previous paper) fuel economy for city and highway drive cycles.

\begin{tabular}{|c|c|c|c|c|}
\hline $\begin{array}{c}\text { Drive } \\
\text { cycles }\end{array}$ & $\begin{array}{c}\text { Simulation } \\
(\mathbf{K m} / \mathbf{L})\end{array}$ & $\begin{array}{c}\text { Experiment } \\
\mathbf{( k m} / \mathbf{L})\end{array}$ & $\begin{array}{c}\text { Difference } \\
(\mathbf{k m} / \mathbf{L})\end{array}$ & $\begin{array}{c}\text { Percentage difference } \\
\mathbf{( \% )}\end{array}$ \\
\hline City & 10.13 & 9.77 & 0.37 & 3.76 \\
\hline Highway & 12.15 & 12.77 & 0.62 & 4.89 \\
\hline
\end{tabular}

\section{Conclusions}

This paper presents the development of a 1.3L Perodua Myvi fuel consumption engine map. The fuel consumption engine map is used in the simulations to calculate the estimated fuel economy of the vehicle driven on a city drive cycle and a highway drive cycle that are based on Malaysian roads. The estimated fuel economy results from the simulations are compared to the ones from the real world and they show similarity with a percentage difference of only $5 \%$. 
The authors would like to thank Universiti Sains Malaysia for providing laboratory facilities and financial assistance under short term grant \#60313026.

\section{References}

1. Trading Economics. (2016, 28 May 2016) Available: http://www.tradingeconomics.com/malaysia/car-production

2. D. Tan. (2011, 30 May 2015). Perodua achieves record sales in 2010. Available: http://paultan.org/2011/01/12/peroduaachieves-record-sales-in-2010-5-year-oldmyviis-still-malaysias-best-selling-car-alza-leads-thempv-charts/

3. C. E. Goering, and H. Cho, "Engine model for mapping BSFC contours," Mathematical and Computer Modelling, vol. 11, pp. 514-518 (1988)

4. D. Ramasamy. "Improvement of in cylinder airflow burning rate for a four stroke spark ignition engine running on compressed natural gas (CNG) fuel" (PHD thesis), Universiti Sains Malaysia, 2014

5. M. I. Ramdan, and L.C. Piew, "Fuel economy comparison of Perodua Myvi passenger vehicle on Malaysian city and highway drive cycles," Journal of Scientific Research and Development, vol. 2, 13, pp. 75-82 (2015)

6. PERODUA. (2013, 30 October 2014). Specification of Perodua Myvi. Available: http://www.perodua.com.my/ourcars/myvi/specifications

7. Toyota Peru. (15 March 2015). Daihatsu Data: 3SZ-VE/K3-VE. Available: http://intranet.toyotaperu.com.pe/tdp_sit/data/DAIHATSU/TERIOS/TERIOS_SHORT /pdf/manual/9514/D55B-2-E.pdf

8. Engineering Tool Box. (30 November 2014). Rolling friction and rolling resistance. Available: http://www.engineeringtoolbox.com/rollingfriction-resistance-d_1303.html

9. Z. Gao, J.C.Conklin, C.S. Daw, and V.K. Chakravathy. "A proposed methodology for estimating transient engine-out temperature and emissions from steady-state maps", International Journal of Engine Research, vol. 11, 2 (2010)

10. Y. Liu, J. Li, and B. Shen. "Research on Driving Cycle of Long distance Passenger Vehicles Based on Principle Component Analysis and Cluster Algorithm". International Journal of Control and Automation, vol. 7, 3, pp. 125-136 (2014)

11. Department of Energy, "Annual Energy Review 2003," Energy Information Administration (EIA), Washington, D.C., USA, (2004)

12. L. Guzzella, A. Sciaretta, "Vehicle propulsion systems: Introduction to modeling and optimization," Springer (2007)

13. M. Abas, O. Salim, R. Martinez-Botas, and S. Rajoo, "Efforts to Establish Malaysian Urban Drive-Cycle for Fuel Economy Analysis," SAE Technical Paper (2014) 